\title{
A comprehensive analysis of NPHS1 gene mutations in patients with sporadic focal segmental glomerulosclerosis
}

\author{
Ling Zhuo', Lulin Huang ${ }^{2}$, Zhenglin Yang ${ }^{2}$, Guisen Li ${ }^{1 *}$ (D) and Li Wang ${ }^{1}$
}

\begin{abstract}
Background: Focal segmental glomerulosclerosis (FSGS) is still one of the common causes of refractory nephrotic syndrome. Nephrin, encoded by podocyte-specific NPHS1 gene, participated in the pathogenesis of FSGS. The sites of NPHS1 mutations in FSGS is not clarified very well. In this study, we investigated the specific mutations of NPHS1 gene in Chinese patients with sporadic FSGS.
\end{abstract}

Methods: A total of 309 patients with sporadic FSGS were collected and screened for NPHS1 mutations by secondgeneration sequencing. The variants were compared with those extracted from 2504 healthy controls in the 1000 Genomes Project. The possible pathogenic roles of missense variants were predicted by three different software. We also compared these candidate causal mutations with those summarized from the previous studies.

Results: Thirty-two genetic mutations of NPHS1 gene were identified in FSGS patients, including 12 synonymous mutations, 17 missense mutations, 1 splicing mutation, and 2 intron mutations, of which c.G3315A (p.S1105S) was the most common variant (261/309). A novel missense mutation c.G2638T (p.V880F) and a novel splicing mutation 35830957 C > T were identified in FSGS patients. The frequencies of the four synonymous mutations (c.C294T [p.1981], c.C2223T [p.T741 T], c.C2289T [p.V763 V], c.G3315A [p.S1105S]) were much higher in FSGS patients than in controls. The frequencies of the four missense mutations (c.G349A [p.E117K], c.G1339A [p.E447K], c.G1802C [p.G601A], c.C2398T [p.R800C]) were much higher and one (c.A3230G [p.N1077S]) was lower in FSGS patients than in controls. Five missense mutations, c.C616A (p.P206T), c.G1802C (p.G601A), c.C2309T (p.P770L), c.G2869C (p.V957 L), and c.C3274T (p.R1092C), were predicted to be pathogenic mutations by software analysis.

Conclusions: NPHS1 gene mutations were quite common in sporadic FSGS patients. We strongly recommend mutation analysis of the NPHS1 gene in the clinical management of FSGS patients.

Keywords: Focal segmental glomerulosclerosis, NPHS1, Mutation, Second-generation sequencing

\section{Background}

Focal segmental glomerulosclerosis (FSGS) is a syndrome with unique clinical and pathological manifestations. Although new medications continue to emerge, FSGS is still one of the most common causes which contributes to refractory nephrotic syndrome [1-3]. The previous studies suggested that FSGS could be idiopathic or secondary to a process originating outside the kidneys as well as to a

\footnotetext{
*Correspondence: guisenli@163.com

'Renal Department and Institute of Nephrology, Sichuan Provincial People's Hospital, School of Medicine, University of Electronic Science and Technology of China, No. 32, West 2nd Duan, 1st Circle Road, Qingyang District, Chengdu, Sichuan 610072, People's Republic of China Full list of author information is available at the end of the article
}

specific genetic mutation $[1,3,4]$, including INF2, ACTN4, TRPC6, WT1, NPHS1, NPHS2, etc. $[5,6]$. The efficacy of cyclosporin A (CsA) is much better in nonhereditary steroid-resistant nephrotic syndrome (SRNS) than in genetic SRNS [7]. It suggests that genetic mutations not only contribute to the pathogenesis of FSGS but also influence the outcome of clinical treatment. Therefore, it is of great clinical significance to elucidate the characteristics of genetic variation for FSGS patients.

About $8-14 \%$ of patients with FSGS could be explained by podocyte-related gene mutations. NPHS1, that relates to congenital nephrotic syndrome (CNS) and SRNS, is one of the most frequently reported genes. 
Initially, Kestilä described NPHS1 as the pathogenic gene of the congenital nephrotic syndrome of the Finnish type (CNF) [8]. The NPHS1 gene (OMIM "602716) locates in the chromosome 19q13.1 and consists of 29 exons that span a $150 \mathrm{~kb}$ region. Nephrin, a transmembrane protein encoded by NPHS1 gene, is one of the important components of slit diaphragm (SD) [9]. As a signaling scaffold via interactions at its short intracellular region, nephrin also serves as the core component of the glomerular filtration barrier [10]. The mutations of NPHS1 gene could lead to the occurrence of different degrees of kidney diseases, however, studies which investigated the relationship between NPHS1 gene mutations and FSGS were limited, especially in China [8, 11-13].

Santin et al selected SRNS patients to conduct a series of research of podocyte-associated genes [6]. The patients showed familiar heredity and 57\% of them developed FSGS at extremely early ages [6]. NPHS1 gene was the most common mutant gene in these subjects, and patients with NPHS1 mutations were more likely to progress to ESRD than those with other podocyte genes [6]. NPHS1 mutations have exhibited increasing prevalence across the world over recent decades, while most of the reports have only focused on one or several mutations of NPHS1 in relatively small FSGS samples. In this study, we performed an analysis of NPHS1 gene mutations in Chinese patients with sporadic FSGS by direct sequencing of all exons. While comparing these variants with the data from 1000 genome project as well as the mutations reported previously, we hoped to further elucidate the characteristics of NPHS1 gene mutations in sporadic FSGS patients and to provide a profile for future precision medicine and pathogenetic studies of FSGS.

\section{Subjects and methods \\ Patient and data recruitment}

A total of 309 biopsy-proved FSGS patients were enrolled in this study. All patients with secondary FSGS and familial FSGS were excluded. The study was approved by the South West research ethics committee and the institutional review board at each recruiting center. The average age of the patients was $32.0 \pm 14.2$ years old (from 10 to 71 years old). The percentage of male patients was $62.0 \%$ (195 cases). The NPHS1 mutations information of 2504 healthy controls was extracted from the 1000 Genome Project (International Genome Sample Resource, IGSR, www.internationalgenome.org).

We summarized the data of NPHS1 gene mutations from previous publications. Detailed mutational information in previous references for retrospective analysis was collected from PUBMED database (https://www. ncbi.nlm.nih.gov/pubmed). All the locations of the mutation sites were determined according to the reference sequence of NPHS1 derived from current assembly GRCh38.p11.

\section{Exome sequencing and variant detection}

Genomic DNA was extracted from peripheral blood using standard methods. An exome sequencing for the first 41 FSGS samples was provided by Axeq Technology Inc., Seoul, Republic of Korea. The sequenced sample was prepared according to the Illumina protocols of Sure Select Target Enrichment System Capture Process. Exome sequencing analysis was performed as described previously [14]. The peripheral blood DNA samples of 268 patients with sporadic FSGS were sequenced by next-generation sequencing. Exon regions of NPHS1 gene were selected and the biotinylated 60 mer probes were designed to tile along with the exons of the genes. Samples were prepared as an Illumina sequencing library, and in the second step, the sequencing libraries were enriched for the target region related genes using the MyGenostics Target Region Enrichment protocol. The captured libraries were sequenced using Illumina HiSeq 2000 Sequencer.

Then these variants were filtered through a stringent strategy. Firstly, the detected variants were annotated and filtered based on public and in-house databases: (i) variants in dbSNP144 (http://www.ncbi.nlm.nih.gov/projects/SNP/); (ii) 1000 Genomes Project (ftp://ftp.1000genomes.ebi.ac.uk/vol1/ftp); and (iii) ESP6500 (http://evs. gs.washington.edu/EVS). Secondly, possible damaging effect of each variant on protein structure/function was predicted by SIFT [15], PolyPhen2 [16] and MutationTaster [17]. For a nonsynonymous single nucleotide variant (SNV), the predicted results of "Probably damaging", "Possible damaging", "Damaging", as well as "Diseasecausing", were recorded.

\section{Mutation analysis}

All variants located in the total 29 exons and exonintron boundaries of NPHS1 were analyzed. All statistical tests were performed on SPSS software Version 17.0 (IBM Corp., USA). Chi-square tests in $2 \times 2$ tables were conducted to compare the mutation distribution between the FSGS patients and healthy controls. Bonferroni-corrected $P$ values $<0.05$ were considered statistically significant.

\section{Ethics and consent to participate}

This study was approved by Institutional Review Boards of the Sichuan Academy of Medical Sciences and Sichuan Provincial People's Hospital. All patients provided informed written consent for the collection of data and genetic analysis obtained. Written informed consent from legal guardians of those under the age of 18 was collected. 


\section{Results}

The variant distributions of NPHS1 in FSGS patients Twenty-two variants of NPHS1 gene were identified in 309 FSGS patients, including 12 synonymous mutations, and 17 missense mutations. Moreover, two mutations were found in introns and one novel splicing mutation $35830957 \mathrm{C}>\mathrm{T}$ was found in exon 28. One more novel missense mutation c.G2638 T (p.V880F) was also identified in FSGS patients. All these mutations were annotated in the domains of nephrin protein (Fig. 1). Mutations mostly affected Ig-like domains of the nephrin protein, the extracellular domain, as well as the intracellular domain.

\section{Synonymous mutations and intron mutations}

Twelve synonymous mutations were found in FSGS patients. Among them, only three mutations had been investigated in previous reports (Table 1 ).

The mutation c.G3315A (p.S1105S) in the exon 26 was the most common variant, the A allele frequency was $84.47 \%(261 / 309)$ in patients and was much higher than the data in controls $(84.47 \%$ vs. $17.01 \%, P=7.02 \times$ $\left.10^{-13}\right)$. The minor allele frequencies of the other three synonymous mutations (c.C294T [p.I98I], 30.10\% vs. 6.27\%, $P=7.51 \times 10^{-30}$; c.C2223T [p.T741 T], $15.21 \%$ vs. $1.24 \%, P=2.50 \times 10^{-25}$; c.C2289T [p.V763 V], $32.04 \%$ vs. $12.14 \%, P=1.61 \times 10^{-13}$ ) were also much higher in FSGS patients than in controls. The common variant c.C294T (p.I98I) located in Ig-1 domain, c.C2223T (p.T741 T) and c.C2289T (p.V763 V) in Ig-7 domain.
Two mutations were found in intron, c.C3286 + 36 T and c. C3481 $+45 \mathrm{~T}$. The minor allele frequency (MAF) of c.C3286+36 T $\left(4.21 \%\right.$ vs. $\left.21.41 \%, P=7.04 \times 10^{-13}\right)$ and c. C3481 $+45 \mathrm{~T}\left(6.80 \%\right.$ vs. $\left.16.97 \%, P=5.48 \times 10^{-13}\right)$ in FSGS patients were much lower than in controls.

\section{Missense mutations and splicing mutations}

Seventeen missense mutations and one splicing mutation were detected in sporadic FSGS patients. A novel mutation c.G2638 T (p.V880F; Bonferroni-corrected P > 0.05 ) in exon 19 at a site of conserved Ig-8 domain, was detected only in one FSGS patient. The splicing mutation $35830957 \mathrm{C}>\mathrm{T}$ was also a novel variant and found only in one patient. The detail information of these mutations was listed in Table 2.

The mutation c.G349A, causing a substitution of glutamic acid by lysine at a site of Ig-1 domain (p.E117K), was the most common variants. The MAF of c.G349A was much higher in FSGS patients than in controls $\left(82.85 \%\right.$ vs. $\left.16.69 \%, P=7.01 \times 10^{-13}\right)$. The MAFs of the other three missense mutations, c.G1339A (p.E447K) (4.53\% vs. $0.64 \%, P=2.54 \times 10^{-5}$ ) in Ig-5 domain, c.G1802C (p.G601A) $\left(2.59 \%\right.$ vs. $\left.0.36 \%, P=6.19 \times 10^{-3}\right)$ in Ig-6 domain, c.C2398T (p.R800C) $(3.24 \%$ vs. $0.16 \%, P=$ $4.78 \times 10^{-6}$ ) in $\mathrm{Ig}-7$ domain, were also much higher in FSGS patients than in controls. One mutation, c.A3230G (p.N1077S), located in the transmembrane domain of nephrin. The MAF of c.A3230G (0.65\% vs. 9.11\%, $P=$ $2.45 \times 10^{-8}$ ) was lower in FSGS patients than in controls.

Ten of the seventeen missense mutations had been reported previously to be related to CNS, SRNS, MCNS,

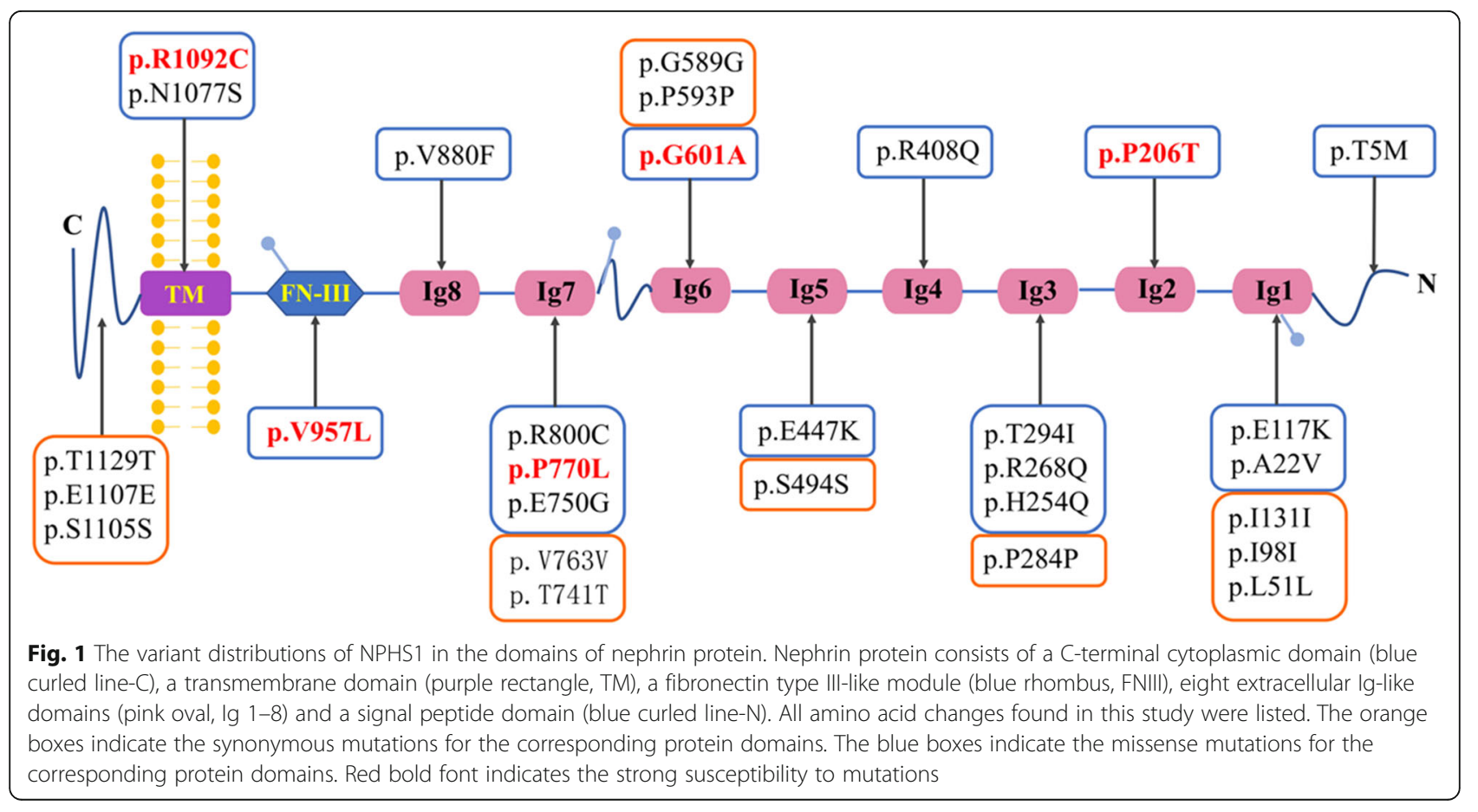


Table 1 The synonymous mutations detected in FSGS patients and compared with controls from 1000 Genomes Project

\begin{tabular}{|c|c|c|c|c|c|c|c|c|c|c|}
\hline Exon & dbSNP144 & Position & $\begin{array}{l}\text { Transcript } \\
\text { consequence }\end{array}$ & $\begin{array}{l}\text { Protein } \\
\text { consequence }\end{array}$ & $\begin{array}{l}\text { Patients } \\
(n=309)\end{array}$ & $\begin{array}{l}\text { Controls } \\
(n=2504)\end{array}$ & $P$ value & $\begin{array}{l}\text { Bonferroni- } \\
\text { corrected } \\
P \text { value }\end{array}$ & $\begin{array}{l}\text { Nephrin } \\
\text { domain }\end{array}$ & $\begin{array}{l}\text { Initial } \\
\text { phenotype }\end{array}$ \\
\hline 2 & rs114385015 & 35851580 & c.C151T & p.L51 L & $2((0.65 \%)$ & $9(0.36 \%)$ & 0.35 & $>0.05$ & $\lg 1$ & Unknown \\
\hline 3 & rs 2285450 & 35851365 & c.C294T & p.1981 & $93(30.10 \%)$ & $157(6.27 \%)$ & $2.35 \times 10^{-31}$ & $7.51 \times 10^{-30}$ & $\lg 1$ & Unknown \\
\hline 3 & rs181246281 & 35851266 & c.C393T & p.1131। & $1(0.32 \%)$ & $1(0.04 \%)$ & 0.21 & $>0.05$ & $\lg 1$ & Unknown \\
\hline 8 & rs763233132 & 35849136 & c.G852A & p.P284P & $1(0.32 \%)$ & 0 & 0.11 & $>0.05$ & $\lg 3$ & Unknown \\
\hline 12 & rs549535993 & 35846153 & c.G1482A & p.S494S & $1(0.32 \%)$ & 0 & 0.11 & $>0.05$ & $\lg 5$ & Unknown \\
\hline 14 & rs 770065180 & 35845519 & c.A1779C & p.P593P & $1(0.32 \%)$ & 0 & 0.11 & $>0.05$ & $\lg 6$ & Unknown \\
\hline 14 & rs768531638 & 35845531 & c.C1767G & p.G589G & $1(0.32 \%)$ & 0 & 0.11 & $>0.05$ & $\lg 6$ & Unknown \\
\hline 17 & rs2073901 & 35843583 & c.C22223T & p.T741 T & 47 (15.21\%) & 31 (1.24\%) & $7.81 \times 10^{-27}$ & $2.50 \times 10^{-25}$ & $\lg 7$ & SRNS [40] \\
\hline 17 & rs437168 & 35843517 & c.C2289T & p.V763 V & 99 (32.04\%) & 304 (12.14\%) & $5.02 \times 10^{-15}$ & $1.61 \times 10^{-13}$ & $\lg 7$ & $\begin{array}{l}\text { SRNS [40], MCNS } \\
{[41]}\end{array}$ \\
\hline 26 & rs115670171 & 35831362 & c.G3321A & p.E1107E & 3 (0.97\%) & 1 (0.04\%) & $4.82 \times 10^{-3}$ & 0.16 & Cy & Unknown \\
\hline 26 & rs780661566 & 35831296 & c.G3387A & p.T1129T & $1(0.32 \%)$ & 0 & 0.11 & $>0.05$ & Cy & Unknown \\
\hline 26 & rs2071327 & 35831368 & c.G3315A & p.S1105S & 261 (84.47\%) & 426 (17.01\%) & $2.20 \times 10^{-14}$ & $7.02 \times 10^{-13}$ & Cy & $\begin{array}{l}\text { SRNS [40], MCNS } \\
{[41]}\end{array}$ \\
\hline Intron & rs466452 & 35831607 & $\begin{array}{l}\text { c.C }(3286+36 \\
T\end{array}$ & - & $13(4.21 \%)$ & $536(21.41 \%)$ & $2.20 \times 10^{-14}$ & $7.04 \times 10^{-13}$ & - & Unknown \\
\hline Intron & rs731934 & 35831008 & $\begin{array}{l}\text { c. C } 3481+ \\
45 T\end{array}$ & - & $21(6.80 \%)$ & 425 (16.97\%) & $1.71 \times 10^{-14}$ & $5.48 \times 10^{-13}$ & - & Unknown \\
\hline
\end{tabular}

Unknown = Have not seen the relevant report at present. Statistical analysis was done by $\mathrm{x}^{2}$ test

Cy C-terminal cytoplasmic, lg immunoglobulin motif

as well as FSGS. But five of them weren't significantly different between FSGS patients and controls after Bonferroni correction (Table 2). The remaining five missense mutations were mentioned above in this study, which distributed differently between FSGS patients and controls.

\section{Pathogenic mutations predicted by software}

We used SIFT, Polyphen and MutationTaster to predict the pathogenicity of the 17 missense mutations in our study. As shown in Table 3, only five mutations, c.C616A (p.P206T), c.G1802C (p.G601A), c.C2309T (p.P770L), c.G2869C (p.V957 L), and c.C3274T (p.R1092C), were predicted to be disease-causing variants by the three different software at the same time. Of the five mutations, only c.G1802C (p.G601A) distributed differently between FSGS patients and controls. Specifically, c.G1802C (p.G601A) and c.G2869C (p.V957 L) have been reported before, both of them were found in Chinese patients. The former study [18] contained the data for the Sanger sequencing of five different podocyte-expressed genes in 38 Chinese children. NPHS1 showed a higher proportion of mutations, and c.G1802C (p.G601A) was illustrated as "likely pathogenic" with the prediction score. The c.G2869C (p.V957 L) was reported in a Chinese CNS family [19], and three heterozygous mutations were identified in NPHS1 gene. This mutation was predicted as "diseasecausing variant" in our study.
The predicted results of the remaining 12 missense mutations were shown in Table 4. The novel mutation c.G2638 T, causing a conservative amino acid substitution of valine by phenylalanine, seemed to be a protective mutation.

\section{Discussion}

Although NPHS1 was first demonstrated to be the causal gene for congenital nephrotic syndrome of Finnish type [20], subsequent studies have confirmed that it was also a causative gene or susceptibility gene for a variety of kidney diseases, such as SRNS, FSGS, minimal change disease with nephrotic syndrome (MCNS), IgA nephropathy, et al. $[9,11,12,21-24]$. Among them FSGS was one of the most common causes of SRNS and a common type of genetically related kidney disease [18, 24, 25]. Most studies about genetic mutations in FSGS were based mainly on familial FSGS patients and lots of FSGS-causing genes have been identified $[1,5]$. Especially in individuals presenting with FSGS or nephrotic syndrome before or at the age of 18 years old, the most common genes in which a mutation was found continues to be limited to only a few genes, including NPHS1 and NPHS2 [2, 23, 26-29].

Nephrin was located only in glomerular podocytes, which participated in intercellular junctions of mature podocyte and formations of the slit diaphragms [30]. It was demonstrated by lowering nephrin expression in an inducible model of nephrin deletion that normal nephrin 
Table 2 The missense and splicing mutations detected in FSGS patients and compared with controls from 1000 Genomes Project

\begin{tabular}{|c|c|c|c|c|c|c|c|c|c|c|}
\hline Exon & dbSNP144 & Position & $\begin{array}{l}\text { Transcript } \\
\text { consequence }\end{array}$ & $\begin{array}{l}\text { Protein } \\
\text { consequence }\end{array}$ & $\begin{array}{l}\text { Patients } \\
(n=309)\end{array}$ & $\begin{array}{l}\text { Controls } \\
(n=2504)\end{array}$ & $P$ value & $\begin{array}{l}\text { Bonferroni-corrected } \\
P \text { value }\end{array}$ & $\begin{array}{l}\text { Nephrin } \\
\text { domain }\end{array}$ & $\begin{array}{l}\text { Initial } \\
\text { phenotype }\end{array}$ \\
\hline \multicolumn{11}{|l|}{ Missense } \\
\hline 1 & rs191850409 & 35851824 & c.C14T & p.T5M & $3(0.97 \%)$ & $3(0.12 \%)$ & 0.020 & $>0.05$ & Sp & Unknown \\
\hline 2 & rs116617171 & 35851666 & c.C65T & p.A22V & $3(0.97 \%)$ & $9(0.36 \%)$ & 0.14 & $>0.05$ & $\lg 1$ & $\begin{array}{l}\text { CNS [42], } \\
\text { SRNS [43] }\end{array}$ \\
\hline 3 & rs3814995 & 35851310 & c.G349A & p.E117K & 256 (82.85\%) & 418 (16.69\%) & $2.19 \times 10^{-14}$ & $7.01 \times 10^{-13}$ & $\lg 1$ & $\begin{array}{l}\text { CNS [42], } \\
\text { MCNS [41] } \\
\text { SRNS/FSGS } \\
\text { [43] }\end{array}$ \\
\hline 6 & rs201822740 & 35849646 & c.C616A & p.P206T & $1(0.32 \%)$ & $1(0.04 \%)$ & 0.21 & $>0.05$ & $\lg 2$ & Unknown \\
\hline 7 & rs201234008 & 35849314 & c.C762A & p.H254Q & $1(0.32 \%)$ & $1(0.04 \%)$ & 0.21 & $>0.05$ & $\lg 3$ & Unknown \\
\hline 7 & rs115308424 & 35849273 & c.G803A & p.R268Q & $5(1.62 \%)$ & 11 (0.44\%) & 0.024 & $>0.05$ & $\lg 3$ & Unknown \\
\hline 8 & rs113825926 & 35849107 & c.C881T & p.T294l & $1(0.32 \%)$ & $8(0.32 \%)$ & 1.00 & $>0.05$ & $\lg 3$ & $\begin{array}{l}\text { MCNS [41], SRNS } \\
\text { [43] }\end{array}$ \\
\hline 10 & rs33950747 & 35848345 & c.G1223A & p.R408Q & $1(0.32 \%)$ & 42 (1.68\%) & 0.081 & $>0.05$ & $\lg 4$ & $\begin{array}{l}\text { CNS }[9,25,42], \\
\text { MCNS }[41], \text { FSGS } \\
{[44]}\end{array}$ \\
\hline 11 & rs28939695 & 35848142 & c.G1339A & p.E447K & 14 (4.53\%) & $16(0.64 \%)$ & $7.93 \times 10^{-7}$ & $2.54 \times 10^{-5}$ & $\lg 5$ & $\begin{array}{l}\text { MsPGN/ FSGS/ } \\
\text { SRNS [18], CNS } \\
{[42], \text { CNF [45] }}\end{array}$ \\
\hline 14 & rs114615449 & 35845496 & c.G1802C & p.G601A & 8 (2.59\%) & 9 (0.36\%) & $1.94 \times 10^{-4}$ & $6.19 \times 10^{-3}$ & $\lg 6$ & SRNS [18] \\
\hline 17 & rs777418609 & 35843557 & c.A2249G & p.E750G & $1(0.32 \%)$ & 0 & 0.11 & $>0.05$ & $\lg 7$ & Unknown \\
\hline 17 & rs115976159 & 358434987 & c.C2309T & p.P770L & $1(0.32 \%)$ & 0 & 0.11 & $>0.05$ & $\lg 7$ & Unknown \\
\hline 18 & rs114896482 & 35842487 & c.C2398T & p.R800C & $10(3.24 \%)$ & $4(0.16 \%)$ & $1.49 \times 10^{-7}$ & $4.78 \times 10^{-6}$ & $\lg 7$ & $\begin{array}{l}\text { SRNS }[18,40] \\
\text { MCNS }[41]\end{array}$ \\
\hline 19 & - & 35842149 & c.G2638T & p.V880F & 1 (0.32\%) & 0 & 0.11 & $>0.05$ & $\lg 8$ & Novel \\
\hline 21 & rs114849139 & 35839554 & c.G2869C & p.V957vL & 3 (0.97\%) & $9(0.36 \%)$ & 0.14 & $>0.05$ & $\mathrm{Fn}$ & CNS $[19,42,46]$ \\
\hline 24 & rs4806213 & 35831699 & C.A3230G & p.N1077s & $2(0.65 \%)$ & $228(9.11 \%)$ & $7.67 \times 10^{-10}$ & $2.45 \times 10^{-8}$ & $\mathrm{Tm}$ & $\begin{array}{l}\text { SRNS [18], CNS } \\
{[25,42], \text { CNF }} \\
{[47-49], \text { MCNS }} \\
{[41]}\end{array}$ \\
\hline 24 & rs199646631 & 35831655 & c.C3274T & p.R1092C & $1(0.32 \%)$ & $1(0.04 \%)$ & 0.21 & $>0.05$ & $\mathrm{Tm}$ & FSGS [18] \\
\hline Splicing & - & 35830957 & $C>T$ & - & 1 (0.32\%) & 0 & 0.11 & $>0.05$ & - & Unknown \\
\hline
\end{tabular}

Unknown = Have not seen the relevant report at present. Statistical analysis was done by $\mathrm{x} 2$ test

$\mathrm{Tm}$ transmembrane domain, Fn fibronectin type III motif, Ig immunoglobulin motif, Sp signal peptide

expression was necessary for podocyte intercellular junction in the glomerulus [31]. A low level of nephrin expression could result in progressive proteinuria with glomerular hypertrophy and FSGS of glomeruli [31, 32]. Nephrin-knockdown mice developed more podocyte apoptosis and depletion after doxorubicin challenge [32]. NPHS1 knockout mice subjected to podocyte injury failed to recover from foot process effacement as well as the persistence of proteinuria [31]. Ephrin-B1, a membrane-bound protein, bound to and interacted with nephrin by immunoprecipitation assay [33]. The phosphorylation of ephrin-B1 enhanced the phosphorylation of nephrin and promoted the phosphorylation of c-Jun $\mathrm{N}$-terminal kinase (JNK), which was required for ephrinB1-promoted cell motility [33]. The interaction of nephrin and ephrin-B1 maintains the structure and

Table 3 The pathogenic mutations predicted by three software for the non-synonymous mutations

\begin{tabular}{lllllll}
\hline Dbsnp144 & Position & Transcript Consequence & Protein Consequence & SIFT & Polyphen & MutationTaster \\
\hline rs201822740 & 35849646 & c.C616A & p.P206T & Damaging & Probably damaging & Disease causing \\
rs114615449 & 35845496 & c.G1802C & p.G601A & Damaging & Probably damaging & Disease causing \\
rs115976159 & 358434987 & c.C2309T & p.P770L & Damaging & Possibly damaging & Disease causing \\
rs114849139 & 35839554 & c.G2869C & p.V957L & Damaging & Probably damaging & Disease causing \\
rs199646631 & 35831655 & c.C3274T & p.R1092C & Damaging & Possibly damaging & Disease causing \\
\hline
\end{tabular}

Three different software are used to predict the likelihood of causing disease: SIFT, Polyphen and MutationTaster 
Table 4 Pathogenicity predicted by three software for the non-synonymous mutations

\begin{tabular}{lllllll}
\hline Dbsnp144 & Position & Transcript Consequence & Protein Consequence & SIFT & Polyphen & MutationTaster \\
\hline rs191850409 & 35851824 & c.C14T & p.T5M & Tolerated & Benign & Polymorphism \\
rs116617171 & 35851666 & c.C65T & p.A22V & Damaging & Benign & Polymorphism \\
rs3814995 & 35851310 & c.G349A & p.E117K & Tolerated & Probably damaging & Polymorphism automatic \\
rs201234008 & 35849314 & c.C762A & p.H254Q & Tolerated & Benign & Polymorphism \\
rs115308424 & 35849273 & c.G803A & p.R268Q & Tolerated & Benign & Polymorphism \\
rs113825926 & 35849107 & c.C881T & p.T2941 & Tolerated & Benign & Polymorphism \\
rs33950747 & 35848345 & c.G1223A & p.R408Q & Tolerated & Probably damaging & Disease causing \\
rs28939695 & 35848142 & c.G1339A & p.E447K & Tolerated & Probably damaging & Disease causing automatic \\
rs777418609 & 35843557 & c.A2249G & p.E750G & Damaging & Possibly damaging & Polymorphism \\
rs114896482 & 35842487 & c.C2398T & p.R800C & Tolerated & Benign & Polymorphism \\
- & 35842149 & c.G2638T & p.V880F & Tolerated & Benign & Polymorphism \\
rs4806213 & 35831699 & c.A3230G & p.N1077S & Damaging & Benign & Polymorphism automatic \\
\hline
\end{tabular}

Three different software are used to predict the likelihood of causing disease: SIFT, Polyphen and MutationTaster

barrier function of the slit diaphragm [33]. It suggested that nephrin was required to maintain slit diaphragm integrity and slit diaphragm-mediated signaling, and it played an important role for the maintenance of podocyte function, production of proteinuria and pathogenesis of FSGS.

So far, more than 220 different mutations have been described affecting most exons in NPHS1 [11]. These mutations have been found in various kidney diseases, however, the relationship between NPHS1 mutation and FSGS was relatively less explored [34-37]. Santin, et al. found that the mutations of NPHS1 gene were detected in patients with CNF, congenital FSGS, childhood FSGS, as well as adulthood FSGS [37]. A previous study reported that no pathogenic NPHS1 mutations were found in 33 FSGS patients with SRNS [36], but the study only explored the previously reported pathogenic mutations in a small FSGS sample. Another study indicated that gene interactions between NPHS1 and TRPC6 variants have important implications on post-transplantation FSGS [35]. In this study, we focused on sporadic FSGS patients to analyze the NPHS1 mutations. We identified 32 mutations in NPHS1 in a relatively large cohort of FSGS patients in China, including two novel mutations.

Twelve synonymous mutations, 17 missense mutations, one splicing mutation and two intron mutations were found in our study. The MAFs of four synonymous mutations (c.C294T [p.I98I], c.C2223T [p.T741 T], c.C2289T [p.V763 V], c.G3315A [p.S1105S]) and four missense mutations (c.G349A [p.E117K], c.G1339A [p.E447K], c.G1802C [p.G601A], c.C2398T [p.R800C]) were much higher in FSGS patients than the data in controls. The MAFs of a missense mutation (c.A3230G [p.N1077S]) and two intron mutations (c.C3286 + 36 T and c. C3481 $+45 \mathrm{~T}$ ) were lower in FSGS patients than the data in controls. Interestingly, of the four synonymous and five missense mutations mentioned above, eight other mutations except synonymous mutation c.C294T (p.I98I) have been reported to be associated with SRNS, MCNS or FSGS (Tables 1 and 2). Five missense mutations, c.C616A (p.P206T), c.G1802C (p.G601A), c.C2309T (p.P770L), c.G2869C (p.V957 L), and c.C3274T (p.R1092C), were predicted to be diseasecausing variants by three different software.

As listed in Table 1, several synonymous mutations were previously reported to be associated with SRNS, MCNS, or FSGS. But the pathogenesis was still unknown. For the missense mutations, although five mutations in our study were reported previously, the exact pathogenesis of these mutations remained unclear, and no appropriate animal model of these mutations has been established for further study. Nephrin contained eight Ig-like domains, a fibronectin type III-like module (Fn), a transmembrane domain and an intracellular domain $[13,38]$. A previous study revealed that most mutations of NPHS1 were observed in Ig-2, Ig-4, and Ig-7 domains [39]. In our study, the differentially distributed mutations in FSGS patients mainly located in Ig-1, Ig-6, Ig-7, and C-terminal cytoplasmic regions. It was also consistent with the concept that Ig-like part of the intracellular domain remained to be crucial for nephrin function [29]. All of the results would be helpful for future pathogenic mechanism research.

\section{Conclusions}

It was demonstrated in our study that the mutations of NPHS1 gene are common in Chinese sporadic FSGS patients. A comprehensive evaluation of NPHS1 mutations would be helpful for the management of FSGS. The mutations of NPHS1 gene could play an important role in the pathogenesis of FSGS, and we still needed more researches to clarify the pathogenesis of these mutations. 


\section{Abbreviations}

ACT4: Actin 4; CNF: Congenital nephrotic syndrome of the Finnish type; CNS: Congenital nephrotic syndrome; CSA: Cyclosporin A; Fn III: Fibronectin type III motif; FSGS: Focal segmental glomerulosclerosis; Ig: Immunoglobulin motif; IGSR: International genome sample resource; INF2: Inverted formin 2; MAF: Minor allele frequency; MCNS: Minimal change nephrotic syndrome; NPHS1: Nephrin; NPHS2: Podocin; OMIM: Online mendelian inheritance in man; SD: Slit diaphragm; SNV: Single nucleotide variant; SRNS: Steroidresistant nephrotic syndrome; TRPC6: Transient receptor potential cation channel, subfamily C, member 6; WT1: Wilms tumor 1

\section{Acknowledgments}

Thanks to 1000 Genomes Project and all people who contribute to this project.

\section{Authors' contributions}

GL conceived of the study and participated in its design, participated in data and genetic analysis, and helped to draft the manuscript. LZ carried out the clinical data collection, variants' confirmation, data and genetic analysis, and drafted the manuscript. LH performed the statistical analysis. LW and ZY participated in the design of the study and coordination. All authors read and approved the final manuscript.

\section{Funding}

This study was supported in part by Youth Science and Technology Creative Research Groups of Sichuan Province (2015TD0013).

\section{Availability of data and materials}

The datasets used and/or analyzed during the current study are available from the corresponding author on reasonable request.

\section{Ethics approval and consent to participate}

This study was approved by Institutional Review Boards of the Sichuan Academy of Medical Sciences and Sichuan Provincial People's Hospital, and informed consent was obtained before study. Written informed consent for the study was obtained from all patients. If the patients were less than 18 years old, the legal guardians of participants under 18 provided written consent.

\section{Consent for publication}

Not applicable

\section{Competing interests}

The authors declare that they have no competing interests.

\section{Author details}

'Renal Department and Institute of Nephrology, Sichuan Provincial People's Hospital, School of Medicine, University of Electronic Science and Technology of China, No. 32, West 2nd Duan, 1st Circle Road, Qingyang District, Chengdu, Sichuan 610072, People's Republic of China. ${ }^{2}$ Key Laboratory for Human Disease Gene Study, Sichuan Provincial People's Hospital, School of Medicine, University of Electronic Science and Technology of China, Chengdu 610072, China.

Received: 20 October 2018 Accepted: 6 June 2019

Published online: 19 June 2019

\section{References}

1. D'Agati VD, Kaskel FJ, Falk RJ. Focal segmental glomerulosclerosis. N Engl J Med. 2011;365(25):2398-411.

2. Philippe A, Nevo F, Esquivel EL, Reklaityte D, Gribouval O, Tete MJ, Loirat C Dantal J, Fischbach M, Pouteil-Noble C, et al. Nephrin mutations can cause childhood-onset steroid-resistant nephrotic syndrome. J Am Soc Nephrol. 2008;19(10):1871-8.

3. De Vriese AS, Sethi S, Nath KA, Glassock RJ, Fervenza FC. Differentiating primary, genetic, and secondary FSGS in adults: a Clinicopathologic approach. J Am Soc Nephrol. 2018;29(3):759-74.

4. de Mik SM, Hoogduijn MJ, de Bruin RW, Dor FJ. Pathophysiology and treatment of focal segmental glomerulosclerosis: the role of animal models. BMC Nephrol. 2013;14:74
5. Rood IM, Deegens JK, Wetzels JF. Genetic causes of focal segmental glomerulosclerosis: implications for clinical practice. Nephrol Dial Transplant. 2012;27(3):882-90

6. Santin S, Bullich G, Tazon-Vega B, Garcia-Maset R, Gimenez I, Silva I, Ruiz P, Ballarin J, Torra R, Ars E. Clinical utility of genetic testing in children and adults with steroid-resistant nephrotic syndrome. Clin J Am Soc Nephrol. 2011;6(5):1139-48.

7. Buscher AK, Beck BB, Melk A, Hoefele J, Kranz B, Bamborschke D, Baig S, Lange-Sperandio B, Jungraithmayr T, Weber LT, et al. Rapid response to Cyclosporin a and favorable renal outcome in nongenetic versus genetic steroid-resistant nephrotic syndrome. Clin J Am Soc Nephrol. 2016;11(2): 245-53.

8. Kestila M, Lenkkeri U, Mannikko M, Lamerdin J, McCready P, Putaala H, Ruotsalainen V, Morita T, Nissinen M, Herva R, et al. Positionally cloned gene for a novel glomerular protein--nephrin--is mutated in congenital nephrotic syndrome. Mol Cell. 1998; (4):575-82.

9. Lenkkeri U, Mannikko M, McCready P, Lamerdin J, Gribouval O, Niaudet PM, Antignac CK, Kashtan CE, Homberg C, Olsen A, et al. Structure of the gene for congenital nephrotic syndrome of the finnish type (NPHS1) and characterization of mutations. Am J Hum Genet. 1999;64(1):51-61.

10. Martin CE, Jones N. Nephrin signaling in the podocyte: an updated view of signal regulation at the slit diaphragm and beyond. Front Endocrinol. 2018:9:302.

11. Nguyen TK, Pham VD, Nguyen TH, Pham TK, Nguyen TQ, Nguyen HH. Three novel mutations in the NPHS1 gene in Vietnamese patients with congenital nephrotic syndrome. Case Rep Genet. 2017;2017:2357282.

12. Heeringa SF, Vlangos CN, Chernin G, Hinkes B, Gbadegesin R, Liu J, Hoskins $B E$, Ozaltin F, Hildebrandt F. Thirteen novel NPHS1 mutations in a large cohort of children with congenital nephrotic syndrome. Nephrol Dial Transplant. 2008:23(11):3527-33.

13. Liu L, Done SC, Khoshnoodi J, Bertorello A, Wartiovaara J, Berggren PO, Tryggvason K. Defective nephrin trafficking caused by missense mutations in the NPHS1 gene: insight into the mechanisms of congenital nephrotic syndrome. Hum Mol Genet. 2001;10(23):2637-44.

14. Zhou Y, Tao S, Chen H, Huang L, Zhu X, Li Y, Wang Z, Lin H, Hao F, Yang Z, et al. Exome sequencing analysis identifies compound heterozygous mutation in ABCA4 in a Chinese family with Stargardt disease. PLoS One. 2014;9(3):e91962.

15. Kumar P, Henikoff $\mathrm{S}, \mathrm{Ng} \mathrm{PC}$. Predicting the effects of coding nonsynonymous variants on protein function using the SIFT algorithm. Nat Protoc. 2009;4(7):1073-81.

16. Adzhubei IA, Schmidt S, Peshkin L, Ramensky VE, Gerasimova A, Bork P, Kondrashov AS, Sunyaev SR. A method and server for predicting damaging missense mutations. Nat Methods. 2010;7(4):248-9.

17. Schwarz JM, Cooper DN, Schuelke M, Seelow D. MutationTaster2: mutation prediction for the deep-sequencing age. Nat Methods. 2014;11(4):361-2.

18. Wang Y, Dang X, He Q, Zhen Y, He X, Yi Z, Zhu K. Mutation spectrum of genes associated with steroid-resistant nephrotic syndrome in Chinese children. Gene. 2017;625:15-20.

19. Shi Y, Ding J, Liu JC, Wang H, Bu DF. NPHS1 mutations in a Chinese family with congenital nephrotic syndrome. Zhonghua Er Ke Za Zhi. 2005;43(11):805-9.

20. Hallman N, Norio R, Kouvalainen K. Main features of the congenital nephrotic syndrome. Acta Paediatr Scand. 1967;56((S173):Suppl 172):175.

21. Hinkes BG, Mucha B, Vlangos CN, Gbadegesin R, Liu J, Hasselbacher K, Hangan D, Ozaltin F, Zenker M, Hildebrandt F. Nephrotic syndrome in the first year of life: two thirds of cases are caused by mutations in 4 genes (NPHS1, NPHS2, WT1, and LAMB2). Pediatrics. 2007;119(4):e907-19.

22. Ismaili K, Pawtowski A, Boyer O, Wissing KM, Janssen F, Hall M. Genetic forms of nephrotic syndrome: a single-center experience in Brussels. Pediatr Nephrol (Berlin, Germany). 2009;24(2):287-94.

23. Schoeb DS, Chernin G, Heeringa SF, Matejas V, Held S, Vega-Warner V, Bockenhauer D, Vlangos CN, Moorani KN, Neuhaus TJ, et al. Nineteen novel NPHS1 mutations in a worldwide cohort of patients with congenital nephrotic syndrome (CNS). Nephrol Dial Transplant. 2010;25(9):2970-6.

24. Lin F, Bian F, Zou J, Wu X, Shan J, Lu W, Yao Y, Jiang G, Gale DP. Whole exome sequencing reveals novel COL4A3 and COL4A4 mutations and resolves diagnosis in Chinese families with kidney disease. BMC Nephrol. 2014;15:175.

25. Cil O, Besbas N, Duzova A, Topaloglu R, Peco-Antic A, Korkmaz E, Ozaltin F. Genetic abnormalities and prognosis in patients with congenital and infantile nephrotic syndrome. Pediatr Nephrol (Berlin, Germany). 2015;30(8): 1279-87. 
26. Sharif B, Barua M. Advances in molecular diagnosis and therapeutics in nephrotic syndrome and focal and segmental glomerulosclerosis. Curr Opin Nephrol Hypertens. 2018;27(3):194-200.

27. Trautmann A, Bodria M, Ozaltin F, Gheisari A, Melk A, Azocar M, Anarat A, Caliskan S, Emma F, Gellermann J, et al. Spectrum of steroid-resistant and congenital nephrotic syndrome in children: the PodoNet registry cohort. Clin J Am Soc Nephrol. 2015;10(4):592-600.

28. Aya K, Shimizu J, Ohtomo Y, Satomura K, Suzuki H, Yan K, Sado Y, Morishima T, Tanaka H. NPHS1 gene mutation in Japanese patients with congenital nephrotic syndrome. Nephrol Dial Transplant. 2009;24(8):2411-4.

29. Beltcheva O, Martin P, Lenkkeri U, Tryggvason K. Mutation spectrum in the nephrin gene (NPHS1) in congenital nephrotic syndrome. Hum Mutat. 2001; 17(5):368-73.

30. Holzman LB, St John PL, Kovari IA, Verma R, Holthofer H, Abrahamson DR. Nephrin localizes to the slit pore of the glomerular epithelial cell. Kidney Int. 1999;56(4):1481-91.

31. Verma R, Venkatareddy M, Kalinowski A, Li T, Kukla J, Mollin A, Cara-Fuentes G, Patel SR, Garg P. Nephrin is necessary for podocyte recovery following injury in an adult mature glomerulus. PLoS One. 2018;13(6):e0198013.

32. Li X, Chuang PY, D'Agati VD, Dai Y, Yacoub R, Fu J, Xu J, Taku O, Premsrirut PK, Holzman LB, et al. Nephrin preserves podocyte viability and glomerular structure and function in adult kidneys. J Am Soc Nephrol. 2015;26(10): 2361-77.

33. Fukusumi $Y$, Zhang $Y$, Yamagishi R, Oda K, Watanabe $T$, Matsui $K$, Kawachi $H$. Nephrin-binding Ephrin-B1 at the slit diaphragm controls podocyte function through the JNK pathway. J Am Soc Nephrol. 2018;29(5):1462-74.

34. Edwards JK. Glomerular disease: TRPC6 and NPHS1 mediate FSGS risk. Nat Rev Nephrol. 2015;11(9):505.

35. Sun ZJ, Ng KH, Liao P, Zhang Y, Ng JL, Liu ID, Tan PH, Chong SS, Chan YH Liu J, et al. Genetic interactions between TRPC6 and NPHS1 variants affect Posttransplant risk of recurrent focal segmental glomerulosclerosis. Am J Transplant Off J Am Soc Transplant Am Soc Transplant Surg. 2015;15(12): 3229-38.

36. Binczak-Kuleta A, Rubik J, Litwin M, Ryder M, Lewandowska K, TarymaLesniak O, Clark JS, Grenda R, Ciechanowicz A. Retrospective mutational analysis of NPHS1, NPHS2, WT1 and LAMB2 in children with steroid-resistant focal segmental glomerulosclerosis - a single-Centre experience. Bosn J Basic Med Sci. 2014;14(2):89-93.

37. Edwards JK. TRPC6 and NPHS1 mediate FSGS risk. Nat Rev Nephrol. 2015;11:505.

38. Bierzynska A, Soderquest K, Koziell A. Genes and podocytes - new insights into mechanisms of podocytopathy. Front Endocrinol. 2014;5:226.

39. Koziell A, Grech V, Hussain S, Lee G, Lenkkeri U, Tryggvason K, Scambler P. Genotype/phenotype correlations of NPHS1 and NPHS2 mutations in nephrotic syndrome advocate a functional inter-relationship in glomerular filtration. Hum Mol Genet. 2002;11(4):379-88.

40. Mao J, Zhang Y, Du L, Dai Y, Gu W, Liu A, Shang S, Liang L. NPHS1 and NPHS2 gene mutations in Chinese children with sporadic nephrotic syndrome. Pediatr Res. 2007;61(1):117-22.

41. Lahdenkari AT, Kestila M, Holmberg C, Koskimies O, Jalanko H. Nephrin gene (NPHS1) in patients with minimal change nephrotic syndrome (MCNS). Kidney Int. 2004;65(5):1856-63.

42. Yang F, Chen Y, Zhang Y, Qiu L, Chen Y, Zhou J. Novel NPHS1 gene mutations in a Chinese family with congenital nephrotic syndrome. J Genet. 2016;95(1):161-6.

43. Suvanto M, Patrakka J, Jahnukainen T, Sjostrom PM, Nuutinen M, Arikoski P, Kataja J, Kestila M, Jalanko H. Novel NPHS2 variant in patients with familial steroid-resistant nephrotic syndrome with early onset, slow progression and dominant inheritance pattern. Clin Exp Nephrol. 2017;21(4):677-84.

44. Lovric S, Fang H, Vega-Warner V, Sadowski CE, Gee HY, Halbritter J, Ashraf S, Saisawat P, Soliman NA, Kari JA, et al. Rapid detection of monogenic causes of childhood-onset steroid-resistant nephrotic syndrome. Clin J Am Soc Nephrol. 2014;9(6):1109-16.

45. Aya K, Tanaka H, Seino Y. Novel mutation in the nephrin gene of a Japanese patient with congenital nephrotic syndrome of the Finnish type. Kidney Int. 2000;57(2):401-4.

46. Spahiu L, Merovci B, Jashari H, Kepuska AB, Rugova BE. Congenital nephrotic syndrome - finish type. Med Arch (Sarajevo, Bosnia and Herzegovina). 2016; 70(3):232-4

47. Guaragna MS, Cleto TL, Souza ML, Lutaif AC, de Castro LC, Penido MG, Maciel-Guerra AT, Belangero VM, Guerra-Junior G, De Mello MP. NPHS1 gene mutations confirm congenital nephrotic syndrome in four Brazilian cases: A novel mutation is described. Nephrology (Carlton, Vic). 2016;21(9): 753-7.

48. Caridi G, Gigante M, Ravani P, Trivelli A, Barbano G, Scolari F, Dagnino M, Murer L, Murtas C, Edefonti A, et al. Clinical features and long-term outcome of nephrotic syndrome associated with heterozygous NPHS1 and NPHS2 mutations. Clin J Am Soc Nephrol. 2009;4(6):1065-72.

49. Gigante M, Monno F, Roberto R, Laforgia N, Assael MB, Livolti S, Caringella A, La Manna A, Masella L, lolascon A. Congenital nephrotic syndrome of the finnish type in Italy: a molecular approach. J Nephrol. 2002;15(6):696-702.

\section{Publisher's Note}

Springer Nature remains neutral with regard to jurisdictional claims in published maps and institutional affiliations.
Ready to submit your research? Choose BMC and benefit from:

- fast, convenient online submission

- thorough peer review by experienced researchers in your field

- rapid publication on acceptance

- support for research data, including large and complex data types

- gold Open Access which fosters wider collaboration and increased citations

- maximum visibility for your research: over $100 \mathrm{M}$ website views per year

At BMC, research is always in progress.

Learn more biomedcentral.com/submissions 